
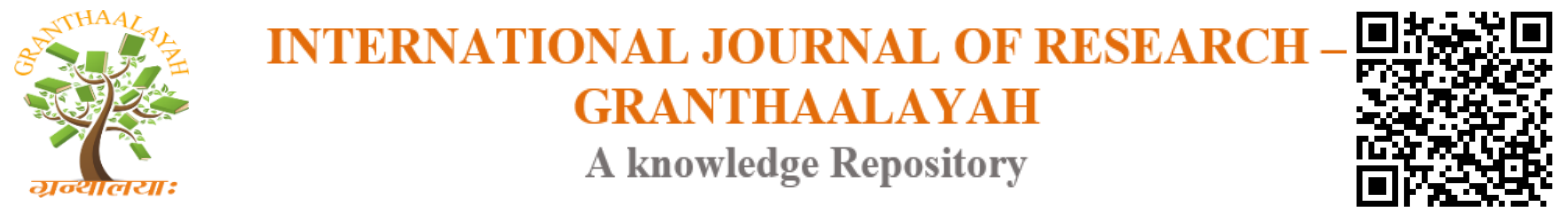

Science

\title{
MULTI-PRODUCT MASTER PRODUCTION SCHEDULING OPTIMIZATION MODELLING USING MIXED INTEGER LINEAR PROGRAMMING AND GENETIC ALGORITHMS
}

\author{
M. S. Al-Ashhab ${ }^{* 1,2}$, Hassan Fadag ${ }^{2}$ \\ ${ }^{1}$ Design and Production Engineering Department Faculty of Engineering, Ain-Shams \\ University- Egypt \\ ${ }^{2}$ Department of Mechanical Engineering, College of Engineering and Islamic Architecture, \\ Umm Al-Qura University, Makkah, Saudi Arabia
}

\begin{abstract}
The objective of this research is to develop a Master Production Scheduling (MPS) model to maximize the total profit using Mixed Integer Linear Programming (MILP). The model is solved using both MILP with the Xpress software and genetic algorithms with the Evolver solver. The model is built for Evolver in MS Excel. Results of both solving tools are compared to analyze the performance of each of them. The accuracy and capability of the model to solve the MPS problems have been verified through the discussion of its results logicality for different cases of different patterns.
\end{abstract}

Keywords: MPS; Genetic Algorithm; Evolver; Xpress; Mixed Integer Linear Programming.

Cite This Article: M. S. Al-Ashhab, and Hassan Fadag. (2018). "MULTI-PRODUCT MASTER PRODUCTION SCHEDULING OPTIMIZATION MODELLING USING MIXED INTEGER LINEAR PROGRAMMING AND GENETIC ALGORITHMS." International Journal of Research - Granthaalayah, 6(5), 78-92. https://doi.org/10.29121/granthaalayah.v6.i5.2018.1429.

\section{Introduction}

MPS optimization has a great effect in any organization in enhancing both owner and customer satisfaction through increasing the profit and maximizing the service level so many of researches have been done to improve and facilitate its application.

N.-P. Lin and L. Krajewski [1] developed a mathematical model for the MPS by an analytical approach using a rolling schedule. F. Herrmann [2] applied linear optimization model for a scheduling problem which is solved with a commercially available tool known as ILOG. PL. K. Palaniappan and N. Jawahar [3] proposes a Genetic Algorithm (GA) to evolve an optimal or near optimal solution for a flow line assembly problem. S. Radhika et al. [4] also solved MPS problems using Differential Evolution (DE) technique, which is heavily dependent on the size of the manufacturing scenario. 
Different solver packages used in solving production optimization problems. Petr Klímek and Martin Kováŕík [5] used MATLAB and Evolver solver tools for determining the optimal production process control.

Many GA solvers have been developed. MATLAB has a separate optimization toolbox that includes a GA-based solver is included within MATLAB [6].

Genetic algorithm is an approach for optimization, which is based on principles of biological evolution. It is usually used for the generation of high-quality solutions for optimization problems. As in genetics, a chromosome is used which is formed of sequential arranged genes. Each one is controlling one or more characters. For chromosome handling, several operators have been proposed, most widely used are selection, crossover, and mutation (Bäck and Schwefel) [7].

The genetic algorithms approach is developed to find the optimal or near optimal solution. Detailed discussion on Gas can be found in books by Holland [8], Michalewicz [9], Gen and Chneg [10], Davis [11], and Goldberg [12].

Al-Ashhab, M. S. et. Al. [13] developed a multi-objective and multi-product MPS model using the lexicographic procedure and used Xpress in solving this model.

Another important solver optimization tool called "Evolver" adopts powerful genetic algorithmbased optimization techniques, which can solve unsolvable problems for other standard linear and nonlinear optimizers [14].

M. S. Al-Ashhab et. Al. [15] developed an MPS optimization model to maximize the profit for a single product and solved it using three different methods; MATLAB linear programming, MATLAB genetic algorithm, and Evolver solver.

In this paper, an MPS model is developed using MILP to maximize the profit. The model is solved using both Xpress solver and Evolver solver. The developed model is formulated in MS Excel environment to be solved using Evolver solver. Results of both solvers are compared to analyze the performance of each of them.

\section{Problem Description and Model Formulation}

\subsection{Problem Description}

The factory has three candidate suppliers and three potential customers located at different distances away from the factory. The Cartesian coordinates of each echelon are shown in Figure 1. The proposed model optimizes the factory production plan for three periods to maximize the total profit for three different products assuming initial and final inventory. The factory is limited by the raw material store, working hours and the final good store's capacities. 


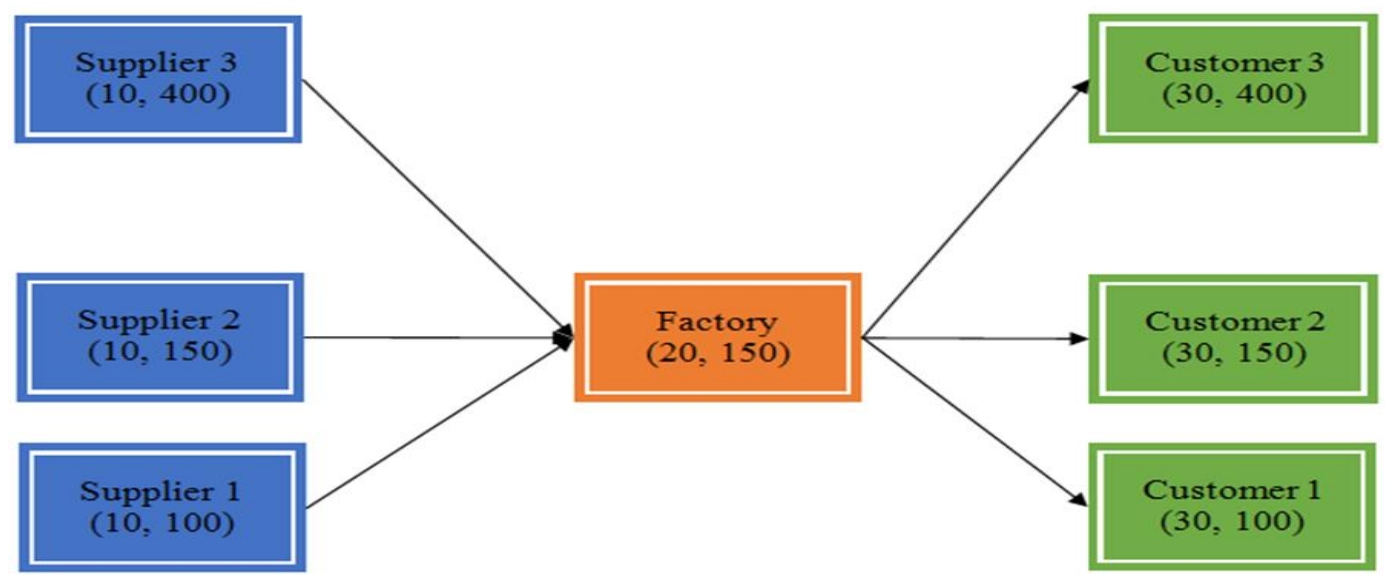

Figure 1: Factory, suppliers, and customers network

\subsection{Model Formulation}

The model involves the following sets, parameters and variables:

\section{Sets}

S: a set of suppliers.

$\mathrm{C}$ : a set of customers.

$\mathrm{T}$ : number of planning periods.

P: a set of products.

\section{Parameters}

Ff: fixed cost,

DEMANDcpt: demand of customer $\mathrm{c}$ from product $\mathrm{p}$ in period $\mathrm{t}$,

IIfp: Initial inventory of product $\mathrm{p}$,

FIfp: Final inventory of product $p$,

Ppct: unit price of product $\mathrm{p}$ at customer $\mathrm{c}$ in period $\mathrm{t}$,

Wp: weight of product $p$,

MHp: processing hours for product $\mathrm{p}$,

Dij: distance facilities i and j,

CAPst: supplier capacity in period $t$,

CAPMft: raw material store,

CAPHft: manufacturing capacity of the factory in hours,

CAPFSft: final product storing capacity,

MatCost: material cost,

MCft: manufacturing cost,

MHp: Required processing hours for product $\mathrm{p}$,

NUCCf: non-utilized capacity cost per hour,

SCPUp: shortage cost per unit per period,

$\mathrm{HC}$ : holding cost per unit weight per period at the factory store,

Bs: batch size from supplier s,

Bfp: batch size from the factory for product $p$,

TC: transportation cost per unit per kilometre, 


\section{Decision Variables}

Qijpt: number of batches transported from facility $\mathrm{i}$ to $\mathrm{j}$ for product $\mathrm{p}$ in period $\mathrm{t}$, Iffpt: number of batches transported to the factory store for product $\mathrm{p}$ in period $\mathrm{t}$, Ifcpt: number of batches transported from the store to customer $\mathrm{c}$ for product $\mathrm{p}$ in period $\mathrm{t}$, Rfpt: residual inventory of the period $t$ at the store of the factory for product $p$. CSLc: Customer Service Level of customer c.

\subsubsection{Objective Function}

Maximizing the profit is the objective of this model. The profit is the difference between the total revenue given in Equation 1 and total cost.

Total Revenue $=\sum_{\mathrm{c} \in \mathrm{C}} \sum_{\mathrm{p} \in \mathrm{P}} \sum_{t \in T}\left(\mathrm{Qfc}_{\mathrm{cpt}}+\mathrm{Ifc}_{\mathrm{cpt}}\right) \mathrm{Bf}_{\mathrm{p}} \mathrm{P}_{\mathrm{pct}}$

\subsubsection{Total Cost Elements}

\section{1) Fixed Cost}

Fixed costs $=F f$

\section{2) Material Cost}

$$
\text { Materialcost }=\sum_{s \in S} \sum_{t \in T} \mathrm{Q}_{\mathrm{sft}} \mathrm{B}_{\mathrm{s}} \operatorname{MatCost}_{\mathrm{st}}+\sum_{p \in P} I I f_{p} \mathrm{~W}_{\mathrm{p}} \operatorname{MatCost}_{\mathrm{s} 1}-\sum_{p \in P} F I f_{p} \mathrm{~W}_{\mathrm{p}} \text { MatCost }_{\mathrm{sT}}
$$

\section{3) Manufacturing Costs}

$$
\begin{aligned}
& \text { Manufacturing costs }=\sum_{c \in C} \sum_{p \in P} \sum_{t \in T} \mathrm{Q}_{\mathrm{fcpt}_{\mathrm{p}}} \mathrm{Bf}_{\mathrm{p}} \mathrm{MH}_{\mathrm{p}} \mathrm{Mc}_{\mathrm{t}}+\sum_{p \in P} \sum_{t \in T} \operatorname{Iff}_{\mathrm{pt}} \mathrm{Bf}_{\mathrm{p}} \mathrm{MH}_{\mathrm{p}} \mathrm{Mc}_{\mathrm{t}}+ \\
& \sum_{p \in P} I I f_{p} \mathrm{MH}_{\mathrm{p}} \mathrm{Mc}_{1}-\sum_{p \in P} F I f_{p} \mathrm{MH}_{\mathrm{p}} \mathrm{Mc}_{\mathrm{T}}
\end{aligned}
$$

\section{4) Non-Utilized Capacity Cost (for the factory)}

$$
N U C C=\sum_{\mathrm{t} \in \mathrm{T}}\left(\left(\mathrm{CAPH}_{\mathrm{ft}}\right) \mathrm{L}_{\mathrm{f}}-\sum_{p \in P} \sum_{\mathrm{c} \in \mathrm{C}}\left(\mathrm{Q}_{\mathrm{fcpt}_{\mathrm{t}}} \mathrm{Bf}_{\mathrm{p}} \mathrm{MH}_{\mathrm{p}}\right)-\sum_{p \in P}\left(\mathrm{Iff}_{\mathrm{pt}} \mathrm{Bf}_{\mathrm{p}} \mathrm{MH}_{\mathrm{p}}\right)\right) N U C C f
$$

\section{5) Shortage Cost (For Customers)}

Shortage cost $=\sum_{p \in P}\left(\sum_{c \in C}\left(\sum_{\mathrm{t} \in \mathrm{T}}\left(\sum_{1}^{\mathrm{t}} \operatorname{DEMAND}_{\mathrm{cpt}}-\sum_{1}^{t}\left(\mathrm{Q}_{\mathrm{fcpt}}+\mathrm{Ifc}_{\mathrm{cpt}}\right) \mathrm{Bf}_{\mathrm{p}}\right)\right) \mathrm{SCPU}_{\mathrm{p}}\right.$ 


\section{6) Transportation COST}

Transportation costs $=\sum_{\mathrm{t} \in \mathrm{T}} \sum_{s \in S} \mathrm{Q}_{\mathrm{sft}} \mathrm{B}_{\mathrm{s}} \mathrm{Tc} \mathrm{D}_{\mathrm{sf}}+\sum_{p \in P}\left(\sum_{t \in T} \sum_{c \in C}\left(\mathrm{Q}_{\mathrm{fcpt}}+\mathrm{Ifc}_{\mathrm{cpt}}\right) \mathrm{Bf}_{\mathrm{p}} \mathrm{W}_{\mathrm{p}} \mathrm{Tc} \mathrm{D}_{\mathrm{fc}}\right.$

\section{7) Inventory Holding Cost}

Holding cost $=\sum_{p \in P} I I f_{\mathrm{pt}} \mathrm{Bf}_{\mathrm{p}} \mathrm{W}_{\mathrm{p}} \mathrm{HC}+\sum_{p \in P} \sum_{t=1}^{T-1} \mathrm{Rf}_{\mathrm{pt}} \mathrm{Bf}_{\mathrm{p}} \mathrm{W}_{\mathrm{p}} \mathrm{HC}$

Equations 2-3 shows that the material and manufacturing costs of the initial inventory are added to the planning horizon costs while the material and manufacturing costs of the final inventory are added to the next planning horizon in which it will be used.

The holding cost is calculated based on the residual inventory of the previous period. So, the holding cost of the beginning inventory is added to the planning horizon, but the holding of the final inventory is not.

\subsubsection{Constraints}

\section{1) Balance Constraints}

$\sum_{s \in S} Q s f_{t} B_{s}=\sum_{c \in C} \sum_{p \in P} Q f c_{c p t} B f_{p} W_{p}+I f f_{p t} B f_{p} W_{p}, \forall t \in T$

$I f f_{p 1} B f_{p}+I I f_{p}=R f_{p 1} B_{f p}+\sum_{c \in C} I f c_{c p 1} B f_{p}, \forall p \in P$

$I f f_{p t} B f_{p}+R f_{p(t-1)} B f_{p}=R f_{p t} B f_{p}+\sum_{c \in C} I f c_{c p t} B f_{p}, \forall t \in 2 \rightarrow T, \forall p \in P$

$R f_{p T} B f_{p}=F I f_{p}, \forall p \in P$

$\left(Q f c_{c p t}+I f c_{c p t}\right) B f_{p} \leq$ DEMAND $_{c p t}+$

$\sum_{1 \rightarrow t}$ DEMAND $_{c p(t-1)}-\sum_{d \in D}\left(Q f c_{c p(t-1)}+I f c_{c p(t-1)}\right) B f_{p}, \forall t \in T, \forall c \in C, \forall p \in P$

Constraints (9-13) ensure balancing of the factory and its store 


\section{2) Capacity Constraints}

$$
\mathrm{Qsf}_{\mathrm{t}} \mathrm{B}_{\mathrm{s}} \leq \mathrm{CAP}_{\mathrm{st}} \mathrm{L}_{\mathrm{s}}, \forall \mathrm{t} \in \mathrm{T}, \forall \mathrm{s} \in \mathrm{S}
$$

$\sum_{s \in S} \mathrm{Qsf}_{\mathrm{t}} \mathrm{B}_{\mathrm{s}} \leq \mathrm{CAPMf}_{\mathrm{t}} \mathrm{L}_{\mathrm{f}}, \forall \mathrm{t} \in \mathrm{T}$

$$
\left(\sum_{\mathrm{c} \in \mathrm{C}} \sum_{\mathrm{p} \in \mathrm{P}} \mathrm{Qfc}_{\mathrm{cpt}} \mathrm{Bf}_{\mathrm{p}}+\sum_{\mathrm{p} \in \mathrm{P}} \mathrm{Iff}_{\mathrm{pt}} \mathrm{Bf}_{\mathrm{p}}\right) \mathrm{MH}_{\mathrm{p}} \leq \mathrm{CAPHf}_{\mathrm{t}} \mathrm{L}_{\mathrm{f}}, \forall \mathrm{t} \in \mathrm{T}
$$

$$
\sum_{p \in P} \mathrm{Rf}_{\mathrm{pt}} \mathrm{Bf}_{\mathrm{p}} \mathrm{W}_{\mathrm{p}} \leq \operatorname{CAPFS}_{\mathrm{t}} \mathrm{L}_{\mathrm{f}}, \forall \mathrm{t} \in \mathrm{T}
$$

Constraints (14-17) ensure that the supplier's, factory, and store's capacities are not exceeded.

All model equations are converted into arrays in MS Excel sheet to be solved using Evolver to find the best values of the variables for optimizing the specified output. Converting all equations into vectors is strenuous and needs more concentration. The model is built in MS Excel and the optimal solution is found using Evolver. Creating realistic models in MS Excel is very powerful since it provides all of the formulas, functions, graphs, and macro capabilities that most researchers need. Although creating the model in MS Excel is preferable by most planners, modelling in MS Excel model is larger than modelling in other software like Xpress.

The model definition in Evolver is shown in Figure 2. In which, Cell CL24 contains the profit. Cells F2:CH2 contain the 81 variables. Cells CJ32:CJ49 and CL32:CL49 contain the capacity constraints. Cells CJ50:CJ91 and CL50:CL91 contain the balancing constraints.

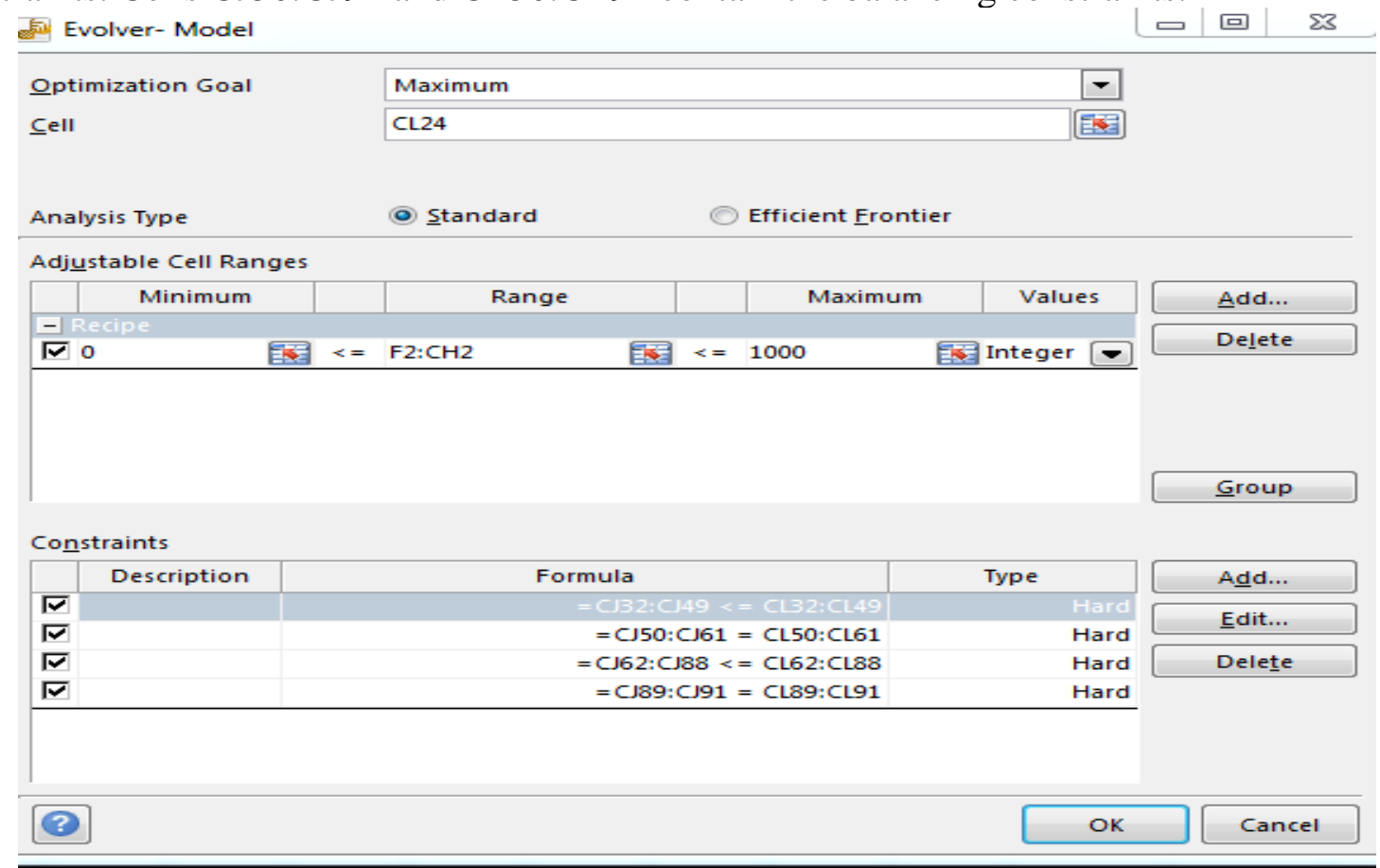

Figure 2: Model definition in Evolver 


\subsection{Model Verification}

In this section, the model accuracy is verified, and the solvers are evaluated. The model is solved using Evolver solver based on GA and using Xpress based on Mixed Integer Linear Programming. The results of the two solvers are compared to analyze the performance of each of them.

Table 1 presents the model parameters.

The model is solved using Evolver and Xpress solver and ran on an Intel® Core $^{\mathrm{TM}}$ i3-2310M CPU @2.10 GHz (3 GB of RAM).

Table 1: Model Parameters

\begin{tabular}{|c|c|c|c|}
\hline Parameter & Value & Parameter & Value \\
\hline Number of Periods & 3 & Supplier batch size & 10 \\
\hline Number of products & 3 & Factory Batch size & 1 \\
\hline Fixed costs $(\$)$ & 50,000 & Holding cost per period $(\$ / \mathrm{kg})$ & 5 \\
\hline $\begin{array}{l}\text { Factory capacity in hours } \\
\text { (hrs.) }\end{array}$ & 12,000 & $\begin{array}{l}\text { The capacity of each supplier } \\
(\mathrm{Kg})\end{array}$ & 12,000 \\
\hline $\begin{array}{l}\text { Weight of products } 1,2,3 \\
\text { (Kg) }\end{array}$ & $1,2,3$ & $\begin{array}{l}\text { Transportation cost per } \mathrm{Km} \text { per } \\
\mathrm{Kg}(\$)\end{array}$ & 0.001 \\
\hline Price of Products & $100,150.200$ & $\begin{array}{l}\text { Machining time of products } 1,2 \text {, } \\
3 \text { (hrs) }\end{array}$ & $1,2,3$ \\
\hline Material Cost $(\$ / \mathbf{k g})$ & 10 & $\begin{array}{l}\text { Capacity of Raw Material Store } \\
(\mathrm{Kg})\end{array}$ & 10,000 \\
\hline Manufacturing Cost (\$/hr) & 10 & Capacity of Factory Store $(\mathrm{Kg})$ & 2,000 \\
\hline 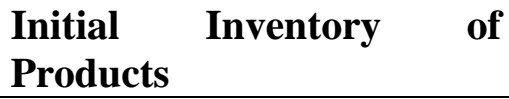 & $50,100,150$ & Final Inventory of Products & $100,150,200$ \\
\hline
\end{tabular}

\subsection{Model Inputs}

The demands of all customers for all products in all periods are shown in Table 2.

Table 2: Demand of each customer

\begin{tabular}{|l|l|l|l|}
\hline Period & Product 1 & Product 2 & Product \\
\hline T 1 & 770 & 770 & 770 \\
\hline T 2 & 590 & 590 & 590 \\
\hline T 3 & 300 & 300 & 300 \\
\hline
\end{tabular}

\subsection{Model Outputs}

Outputs of the model are the values of the eighty-one variable which produce the optimal solution for the maximum profit. The Quantities supplied to the factory, delivered directly from the factory and indirectly from the factory store to customers of both solver are shown in Table 3-5. And the quantities transferred to the factory store and the residual inventories at the end of each period are shown in Table 6-7. 
Table 3: Quantities transferred from suppliers to the factory of both Evolver and Xpress

\begin{tabular}{|l|l|l|l|l|}
\hline Period & QFS1 & QFS2 & QFS3 & Weight \\
\hline 1 & 0 & 1000 & 0 & 10000 \\
\hline 2 & 0 & 1000 & 0 & 10000 \\
\hline 3 & 0 & 1000 & 0 & 10000 \\
\hline Total & 0 & 3000 & 0 & 30000 \\
\hline
\end{tabular}

Table 4: Quantities transferred from factory to customers

\begin{tabular}{|c|c|c|c|c|c|c|c|c|c|c|c|}
\hline \multirow[t]{2}{*}{ Solver } & \multirow[t]{2}{*}{ Period } & \multicolumn{3}{|c|}{ QFC1 } & \multicolumn{3}{|c|}{ QFC2 } & \multicolumn{3}{|c|}{ QFC3 } & \multirow[t]{2}{*}{ Weight } \\
\hline & & P1 & $\mathbf{P 2}$ & P3 & P1 & P2 & P3 & P1 & P2 & P3 & \\
\hline \multirow{3}{*}{ 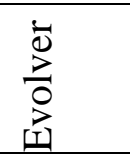 } & 1 & 770 & 770 & 0 & 770 & 770 & 337 & 719 & 670 & 770 & 10000 \\
\hline & 2 & 0 & 0 & 1000 & 590 & 590 & 760 & 0 & 590 & 590 & 10000 \\
\hline & 3 & 890 & 890 & 660 & 300 & 300 & 413 & 891 & 300 & 240 & 9000 \\
\hline \multicolumn{2}{|c|}{ Total Weight } & \multicolumn{10}{|c|}{29000} \\
\hline \multirow{3}{*}{ 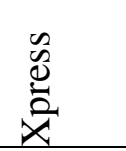 } & 1 & 770 & 20 & 770 & 720 & 770 & 770 & 770 & 770 & 0 & 10000 \\
\hline & 2 & 590 & 0 & 550 & 590 & 590 & 590 & 590 & 0 & 1210 & 10000 \\
\hline & 3 & 300 & 1540 & 340 & 300 & 300 & 300 & 300 & 890 & 240 & 9000 \\
\hline \multicolumn{2}{|c|}{ Total Weight } & \multicolumn{10}{|c|}{29000} \\
\hline
\end{tabular}

Table 5: Quantities transferred from factory store to customers

\begin{tabular}{|c|c|c|c|c|c|c|c|c|c|c|c|}
\hline \multirow[t]{2}{*}{ Solver } & \multirow[t]{2}{*}{ Period } & \multicolumn{3}{|c|}{ IFC1 } & \multicolumn{3}{|c|}{ IFC2 } & \multicolumn{3}{|c|}{ IFC3 } & \multirow[t]{2}{*}{ Weight } \\
\hline & & P1 & $\mathbf{P 2}$ & P3 & P1 & $\mathbf{P 2}$ & P3 & P1 & $\mathbf{P 2}$ & P3 & \\
\hline \multirow{3}{*}{$\begin{array}{l}\overrightarrow{0} \\
\stackrel{\overrightarrow{0}}{0} \\
\dot{0}\end{array}$} & 1 & 0 & 0 & 0 & 0 & 0 & 150 & 50 & 100 & 0 & 700 \\
\hline & 2 & 0 & 0 & 0 & 0 & 0 & 0 & 0 & 0 & 0 & 0 \\
\hline & 3 & 0 & 0 & 0 & 0 & 0 & 0 & 0 & 0 & 0 & 0 \\
\hline \multicolumn{2}{|l|}{ Total } & \multicolumn{10}{|c|}{700} \\
\hline \multirow{3}{*}{$\begin{array}{l}\tilde{d} \\
\hat{d} \\
\hat{x}\end{array}$} & 1 & 0 & 100 & 0 & 50 & 0 & 0 & 0 & 0 & 150 & 700 \\
\hline & 2 & 0 & 0 & 0 & 0 & 0 & 0 & 0 & 0 & 0 & 0 \\
\hline & 3 & 0 & 0 & 0 & 0 & 0 & 0 & 0 & 0 & 0 & 0 \\
\hline \multicolumn{2}{|l|}{ Total } & \multicolumn{10}{|c|}{700} \\
\hline
\end{tabular}

Table 6: Quantities transferred from factory to its store of both solvers

\begin{tabular}{|l|l|l|l|l|}
\hline \multirow{2}{*}{ Period } & \multicolumn{3}{|c|}{ IFF } & \multirow{2}{*}{ Weight } \\
\cline { 2 - 4 } & P1 & P2 & P3 & \\
\hline 1 & 0 & 0 & 0 & 0 \\
\hline 2 & 0 & 0 & 0 & 0 \\
\hline 3 & 100 & 150 & 200 & 1000 \\
\hline
\end{tabular}

Table 7: Residual inventory in the store at the end of each period of both solvers

\begin{tabular}{|l|l|l|l|l|}
\hline \multirow{2}{*}{ Period } & \multicolumn{3}{|c|}{ Rf } & \multirow{2}{*}{ Weight } \\
\cline { 2 - 4 } & P1 & P2 & P3 & \\
\hline 1 & 0 & 0 & 0 & 0 \\
\hline 2 & 0 & 0 & 0 & 0 \\
\hline 3 & 100 & 150 & 200 & 1000 \\
\hline Total & $\mathbf{1 0 0}$ & $\mathbf{1 5 0}$ & $\mathbf{2 0 0}$ & $\mathbf{1 0 0 0}$ \\
\hline
\end{tabular}




\subsection{Results Discussion}

The quantities demanded, received, and the shortages of each product in each period using Evolver are presented in Table 8. It can be noticed that the final shortage of 60 items has occurred only at the third customer who is the furthest to the factory to minimize the transportation cost. The minimum intermediate shortage of 283 items has occurred at the second customer which is the nearest to the factory.

Table 8: Demand, received, and shortage quantities of all products in each period of Evolver

\begin{tabular}{|c|c|c|c|c|c|c|c|c|c|c|}
\hline & \multirow[t]{2}{*}{ Period } & \multicolumn{3}{|c|}{ Product 1} & \multicolumn{3}{|c|}{ Product 2} & \multicolumn{3}{|c|}{ Product 3} \\
\hline & & Dem. & Rec. & Short. & Dem. & Rec. & Short. & Dem. & Rec. & Short. \\
\hline \multirow{4}{*}{ 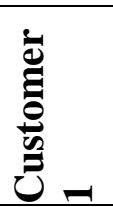 } & 1 & 770 & 770 & 0 & 770 & 770 & 0 & 770 & 0 & 770 \\
\hline & 2 & 590 & 0 & 590 & 590 & 0 & 590 & 590 & 1000 & -410 \\
\hline & 3 & 300 & 890 & -590 & 300 & 890 & -590 & 300 & 660 & -360 \\
\hline & & \multicolumn{2}{|c|}{ Final Shortage } & 0 & \multicolumn{2}{|c|}{ Final Shortage } & 0 & \multicolumn{2}{|c|}{ Final Shortage } & 0 \\
\hline \multirow{4}{*}{ 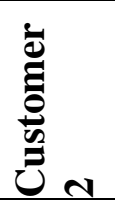 } & 1 & 770 & 770 & 0 & 770 & 770 & 0 & 770 & 487 & 283 \\
\hline & 2 & 590 & 590 & 0 & 590 & 590 & 0 & 590 & 760 & -170 \\
\hline & 3 & 300 & 300 & 0 & 300 & 300 & 0 & 300 & 413 & -113 \\
\hline & & \multicolumn{2}{|c|}{ Final Shortage } & 0 & \multicolumn{2}{|c|}{ Final Shortage } & 0 & \multicolumn{2}{|c|}{ Final Shortage } & 0 \\
\hline \multirow{4}{*}{ 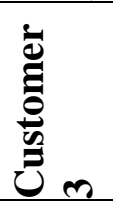 } & 1 & 770 & 769 & 1 & 770 & 770 & 0 & 770 & 770 & 0 \\
\hline & 2 & 590 & 0 & 590 & 590 & 590 & 0 & 590 & 590 & 0 \\
\hline & 3 & 300 & 891 & -591 & 300 & 300 & 0 & 300 & 240 & 60 \\
\hline & & \multicolumn{2}{|c|}{ Final Shortage } & 0 & \multicolumn{2}{|c|}{ Final Shortage } & 0 & \multicolumn{2}{|c|}{ Final Shortage } & 60 \\
\hline
\end{tabular}

The quantities demanded and received by the customers and the shortage of each product in each period using Xpress are presented in Table 9. It can be noticed that the final shortage of 60 items also has been occurred only at the third customer who is the furthest to the factory to minimize the transportation cost. There is no shortage at all has been occurred at the second customer which is the closest to the factory.

Table 9: Demand, received, and shortage quantities of all products in each period of Xpress

\begin{tabular}{|c|c|c|c|c|c|c|c|c|c|c|}
\hline & \multirow[t]{2}{*}{ Period } & \multicolumn{3}{|c|}{ Product 1} & \multicolumn{3}{|c|}{ Product 2} & \multicolumn{3}{|c|}{ Product 3} \\
\hline & & Dem. & Rec. & Short. & Dem. & Rec. & Short. & Dem. & Rec. & Short. \\
\hline \multirow{4}{*}{$\underbrace{}_{-1}$} & 1 & 770 & 770 & 0 & 770 & 120 & 650 & 770 & 770 & 0 \\
\hline & 2 & 590 & 590 & 0 & 590 & 0 & 590 & 590 & 550 & 40 \\
\hline & 3 & 300 & 300 & 0 & 300 & 1540 & -1240 & 300 & 340 & -40 \\
\hline & & \multicolumn{2}{|c|}{ Final Shortage } & 0 & \multicolumn{2}{|c|}{ Final Shortage } & 0 & \multicolumn{2}{|c|}{ Final Shortage } & 0 \\
\hline \multirow{4}{*}{$\underbrace{}_{\mathrm{N}}$} & 1 & 770 & 770 & 0 & 770 & 770 & 0 & 770 & 770 & 0 \\
\hline & 2 & 590 & 590 & 0 & 590 & 590 & 0 & 590 & 590 & 0 \\
\hline & 3 & 300 & 300 & 0 & 300 & 300 & 0 & 300 & 300 & 0 \\
\hline & & \multicolumn{2}{|c|}{ Final Shortage } & 0 & \multicolumn{2}{|c|}{ Final Shortage } & 0 & \multicolumn{2}{|c|}{ Final Shortage } & 0 \\
\hline \multirow{4}{*}{ 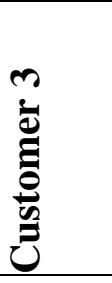 } & 1 & 770 & 770 & 0 & 770 & 770 & 0 & 770 & 150 & 620 \\
\hline & 2 & 590 & 590 & 0 & 590 & 0 & 590 & 590 & 1210 & -620 \\
\hline & 3 & 300 & 300 & 0 & 300 & 890 & -590 & 300 & 240 & 60 \\
\hline & & \multicolumn{2}{|c|}{ Final Shortage } & 0 & \multicolumn{2}{|c|}{ Final Shortage } & 0 & \multicolumn{2}{|c|}{ Final Shortage } & 60 \\
\hline
\end{tabular}


The relationships between the demands of customer, supplied to factory, delivered to customer, residual in factory store and capacity of the factory for both solvers are shown in Figure 3. Relationship between the demands of the customers, supplied to the factory, delivered to the customer, residual in factory store and capacity of the factory of both solvers in which it is noticed that in the first period, the equivalent required weight of $13860 \mathrm{~kg}$ exceeds the material capacity of the factory of $10000 \mathrm{~kg}$. The equivalent delivered of $10700 \mathrm{~kg}$ exceeds the capacity and the supplied material by $700 \mathrm{~kg}$ because of using the initial inventory yielding a shortage of 3160 hours. In the second period, the equivalent required the weight of $10620 \mathrm{~kg}$ exceeds the factory capacity by $620 \mathrm{~kg}$. In the third period, the equivalent delivered of $9000 \mathrm{~kg}$ exceeds the demand the third period of $5400 \mathrm{~kg}$ by $3600 \mathrm{~kg}$ to satisfy as possible the shortage of the last periods and the mandatory final inventory of $1000 \mathrm{hr}$.

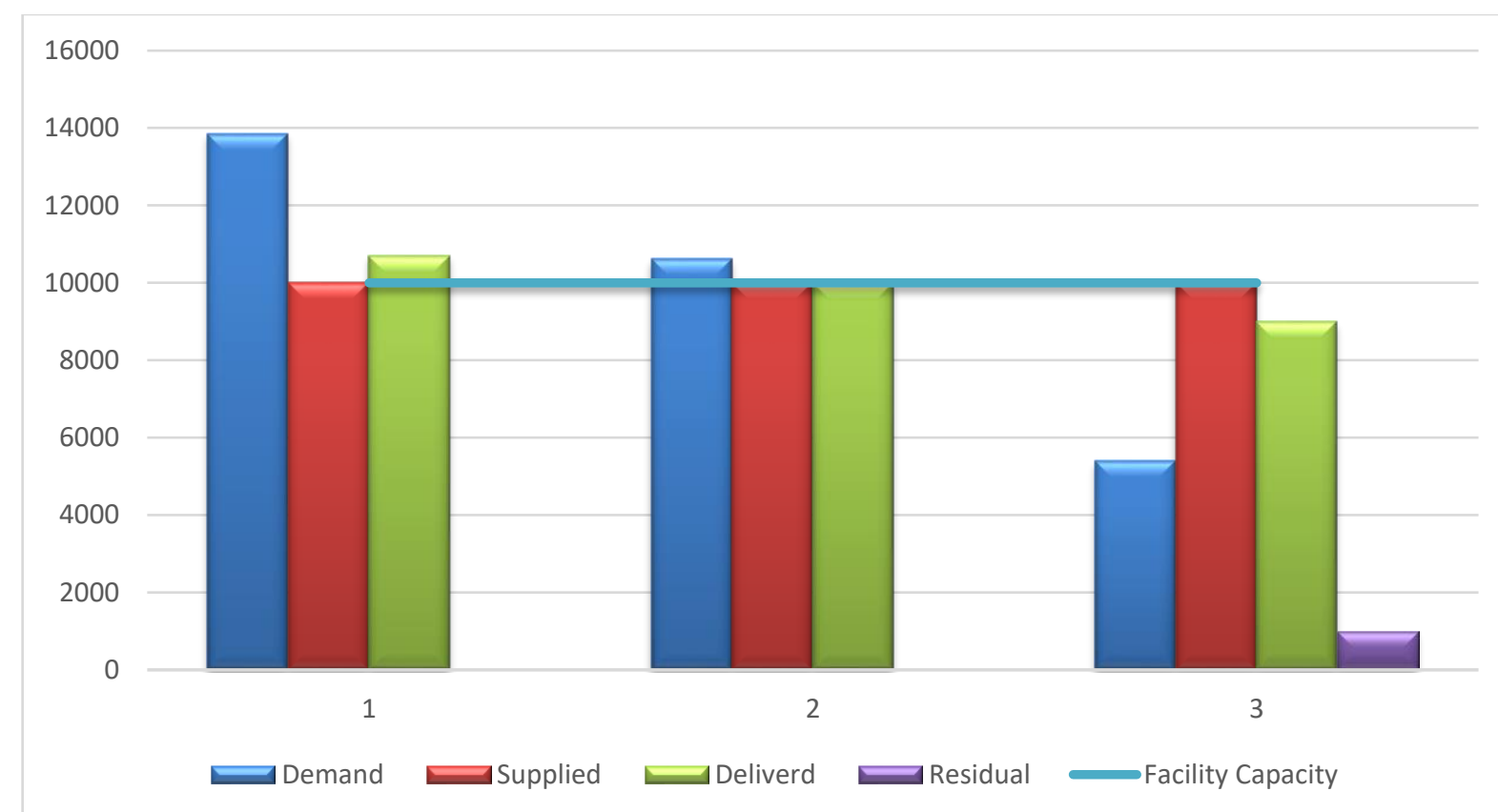

Figure 3: Relationship between the demands of the customers, supplied to the factory, delivered to the customer, residual in factory store and capacity of the factory of both solvers

The balance of flow during the three periods is shown in Figure 4. The quantity of inflow material to the factory equals the sum of the outflow from it. In each period, the sum of beginning inventory and additions equals the sum of ending inventory and the withdrawal from inventory. 
Period \# 1

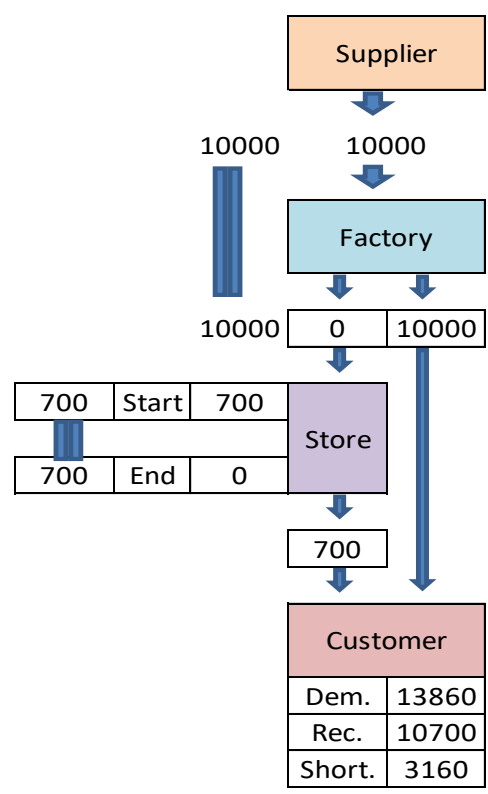

Period \# 2

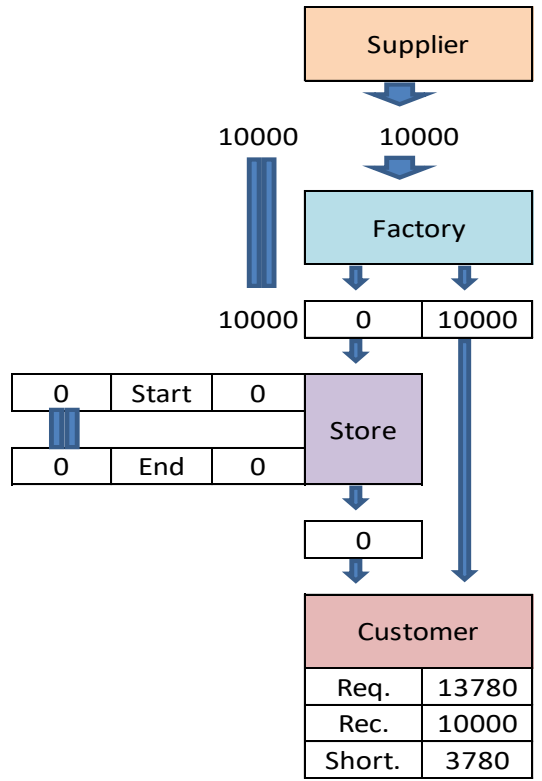

DOI: 10.5281/zenodo.1255237

Period \# 3

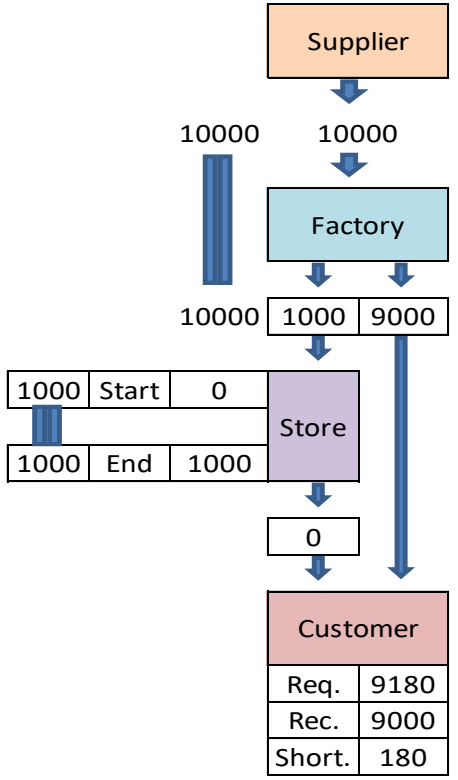

Figure 4: Flow balancing of weights during the first three periods

Both methods gives the same value of optimal profit in addition to the same values of all costs and revenues as presented in Table 10 and the same customers' service levels shown in Figure 5. The Overall Service Level (OSL) is calculated using Equation 18.

$\mathrm{OSL}_{\mathrm{c}}=\sum_{\mathrm{p} \in \mathrm{P}} \sum_{t \in T}\left(\mathrm{Qfc}_{\mathrm{cpt}}+\mathrm{Ifc}_{\mathrm{cpt}}\right) * \mathrm{Bf}_{\mathrm{p}} * \mathrm{~W}_{\mathrm{p}} / \sum_{\mathrm{p} \in \mathrm{P}} \sum_{t \in T} \mathrm{DEMAND}_{\mathrm{cpt}} * \mathrm{~W}_{\mathrm{p}}$

Table 10: Cost/Revenue Values

\begin{tabular}{|l|l|l|l|l|l|}
\hline Cost & Evolver & Xpress & Cost / Revenue & Evolver & Xpress \\
\hline Fixed & 50,000 & 50,000 & Non-Utilized Capacity Cost & 30,000 & 30,000 \\
\hline Holding & 3,500 & 3,500 & Transportation Cost & 33,544 & 33,544 \\
\hline Material & 297,000 & 297,000 & Total cost & 746,644 & 746,644 \\
\hline Manufacturing & 297,000 & 297,000 & Total Revenue & $2,229,000$ & $2,229,000$ \\
\hline Shortage & 35,600 & 35,600 & Total Profit & $\mathbf{1 , 4 5 2 , 3 5 6}$ & $\mathbf{1 , 4 5 2 , 3 5 6}$ \\
\hline
\end{tabular}

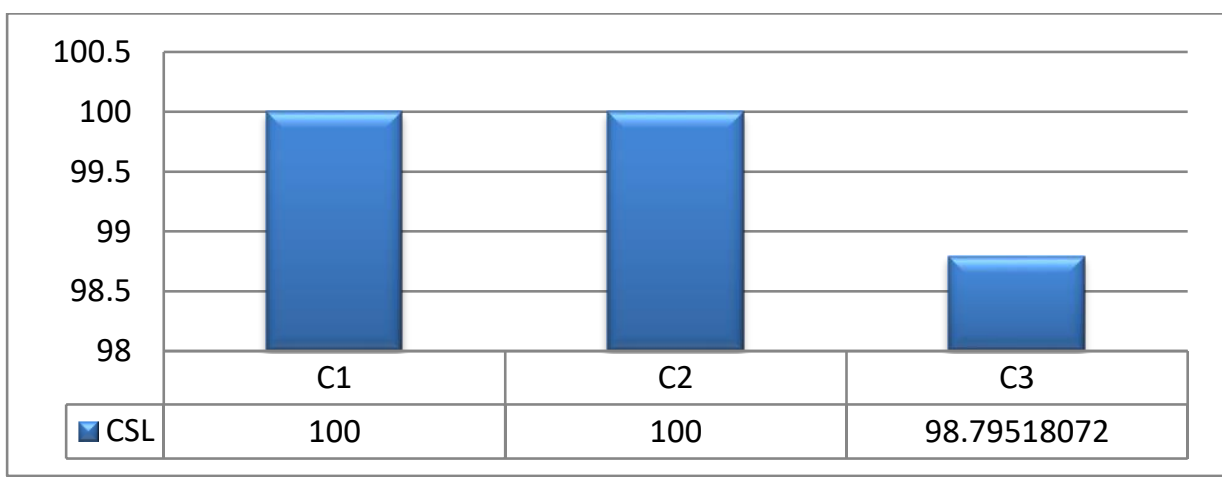

Figure 5: Customers' service levels 


\section{Computational Results}

The model is used in solving five different cases of different demand patterns shown in Figure 6 and the results are presented and analyzed to verify the accuracy and capability of the model.

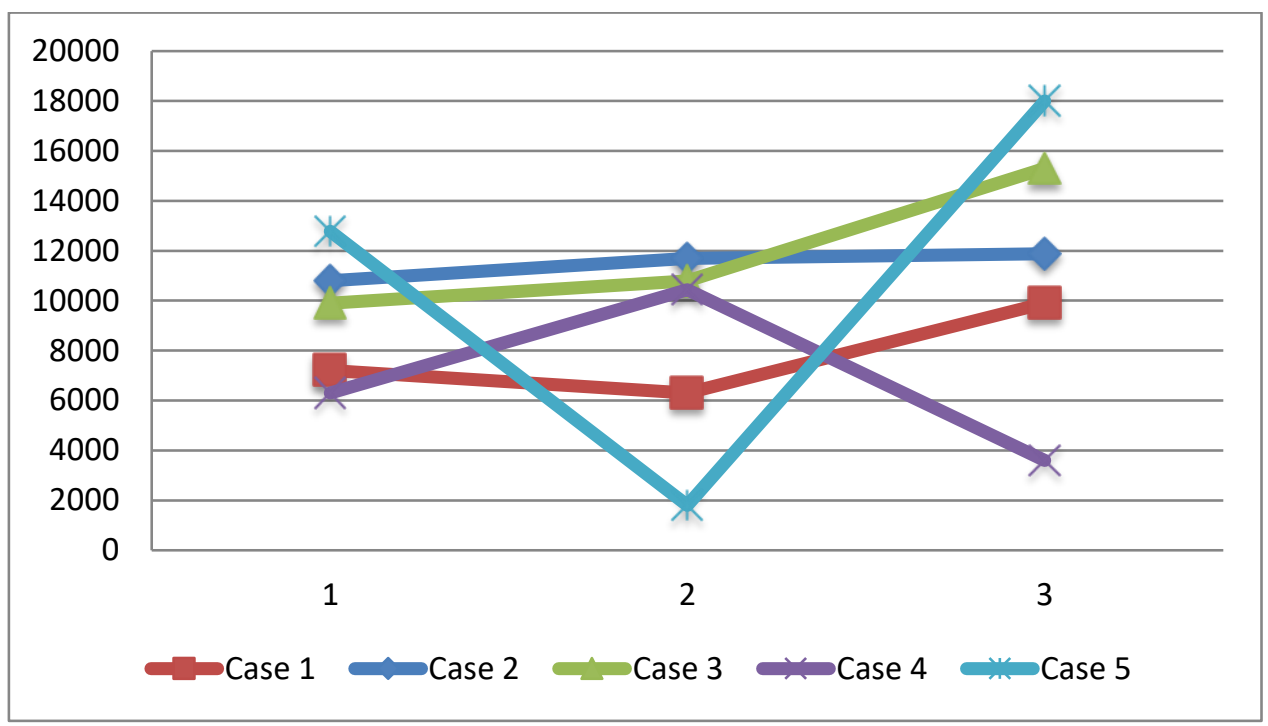

Figure 6: Demand patterns of the five cases

\subsection{Case 1}

As shown in Figure 7 it is noticed that the required weights of 7200, 6300, and 9900 are less than the manufacturing capacity in all periods so the factory satisfied all demands without any shortage.

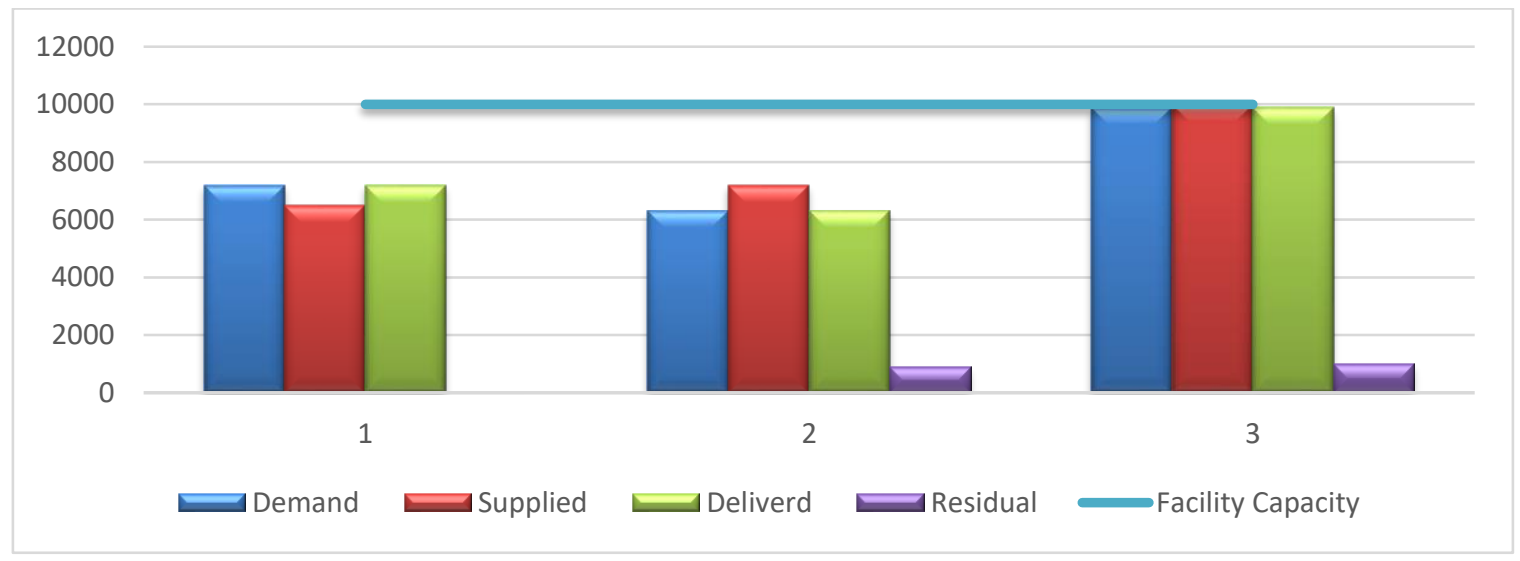

Figure 7: Results of Case 1

\subsection{Case 2}

As shown in Figure 8 it is noticed that the required weights of 10800, 11700 and $11880 \mathrm{Kgs}$ exceed the manufacturing capacity in all periods, so the factory did not satisfy all demands without any shortage. 


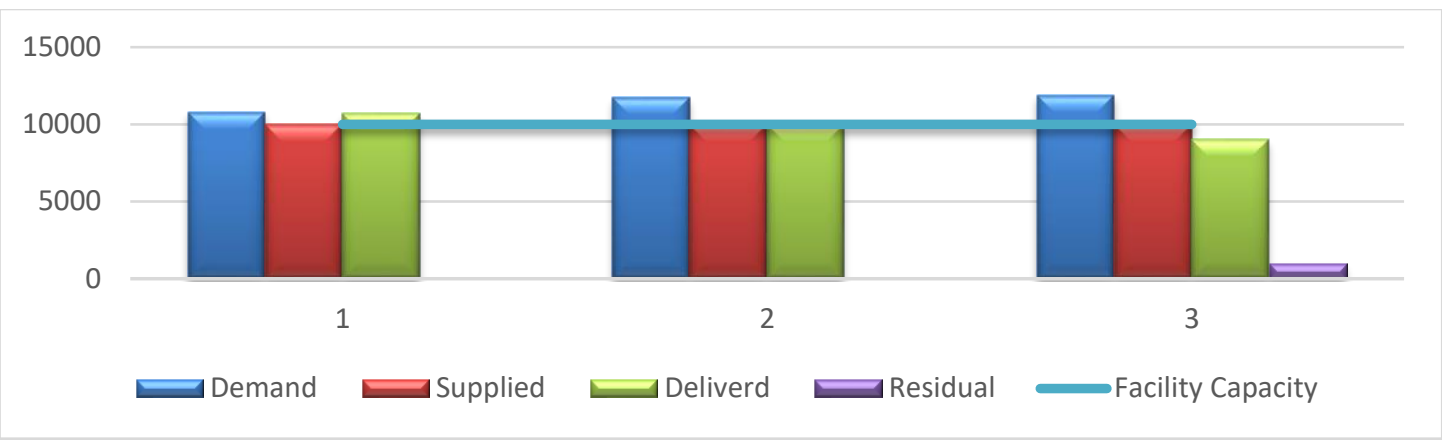

Figure 8: Results of Case 2

\subsection{Case 3}

As shown in Figure 9 it is noticed that the required weights of 9900, 10800 and $15300 \mathrm{Kg}$, the demand of the first period is satisfied, and the beginning inventory had been held to the second period to satisfy the extra demand but the demand of the third period had not been satisfied.

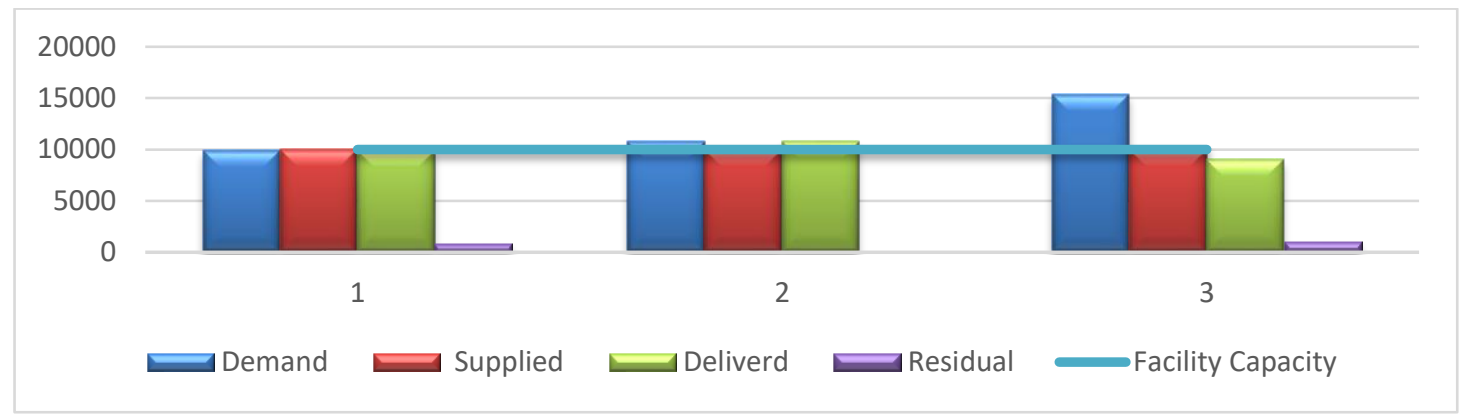

Figure 9: Results of Case 3

\subsection{Case 4}

As shown in Figure 10 it is noticed that the required weights of 6300, 10440 and $3600 \mathrm{Kgs}$ exceeds the capacity of the factory only In period 2 so the factory held some inventory in the first period after satisfying its demand to the satisfy some of the extra demand of the second period while if satisfied the remaining shortage in the third period of low demand. Because of the equality between the shortage and the holding costs for all products the model decided to hold some inventory and satisfy the shortage later.

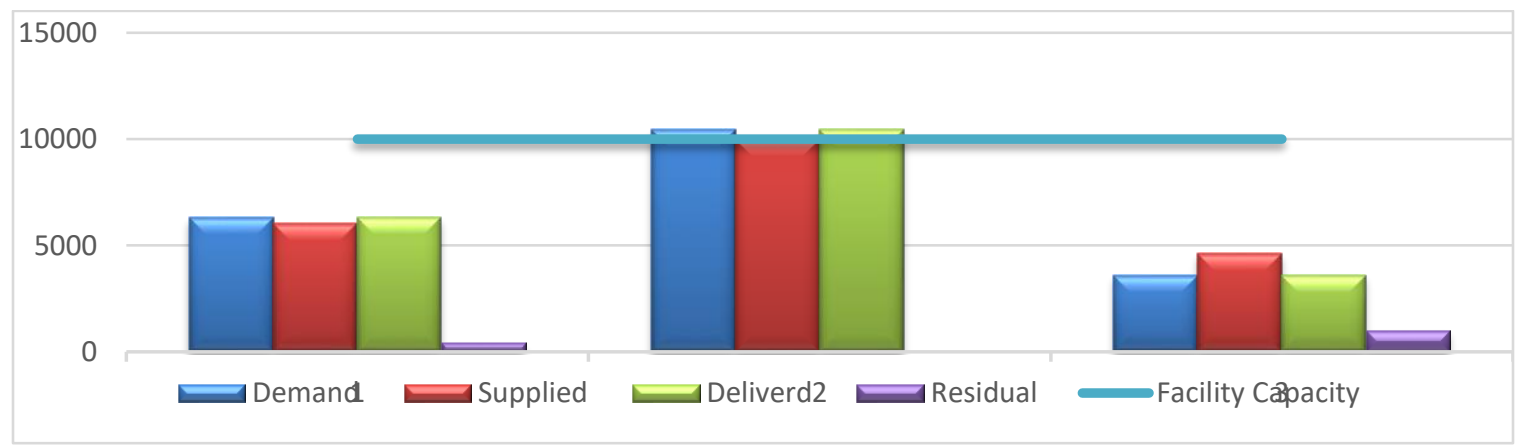

Figure 10: Results of Case 4 


\subsection{Case 5}

As shown in Figure 11 it is noticed that the required weights of 12780,1800 and $18000 \mathrm{Kg} 3 \mathrm{~s}$, the factory delivered 10700 using its full capacity in addition to the beginning inventory to satisfy the demand of the first period and satisfy the remaining at the second period of the very low demand which gave the opportunity to hold the maximum possible inventory of 2000 to satisfy some of the extra demand in period 3.

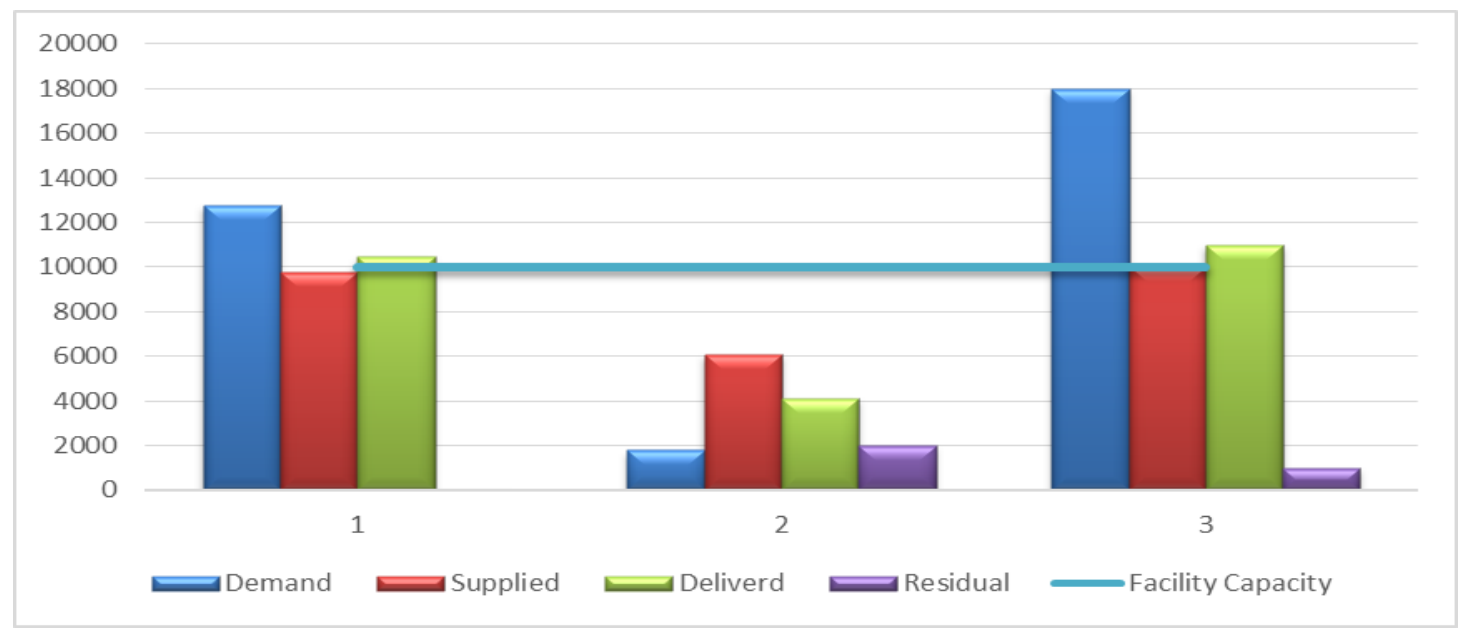

Figure 11: Results of Case 5

\section{Conclusion}

The developed MPS optimization model to maximize the profit using mixed integer linear programming is solved using both Mixed Integer Linear Programming in Xpress software and genetic algorithms in Evolver solver.

The developed model is built in MS Excel environment to be solved using Evolver solver. Results of both software are compared to analyze the capability of each of them. Both solvers gave the same optimal value with different values of some of the variables.

Solving this MPS problem using Evolver based on MS Excel is preferable for the majority of planners where they are familiar enough in using MS Excel sheets without the need to coding the model in any of the programming languages.

The accuracy and capability of the model to solve the MPS problems have been verified through the discussion of its results logicality for different cases of different patterns.

\section{References}

[1] N.-P. Lin and L. Krajewski, "A Model for Master Production Scheduling in Uncertain Environments," Decision Sciences, vol. 23, pp. 839-861, 1992.

[2] F. Herrmann, "Using Optimization Models for Scheduling in Enterprise Resource Planning Systems," Systems, vol. 4, p. 15, 2016. 
[3] P. K. Palaniappan and N. Jawahar, "A genetic algorithm for simultaneous optimisation of lot sizing and scheduling in a flow line assembly," International Journal of Production Research, vol. 49, pp. 375-400, 2011.

[4] S. Radhika, C. S. Rao, and K. K. Pavan, "A differential evolution based optimization for master production scheduling problems," International Journal of Hybrid Information Technology, vol. 6, pp. 163-170, 2013.

[5] P. Klímek and M. Kovárík, "Genetic Algorithms as a Tool of Production Process Control," Journal of Systems Integration, vol. 5, p. 57, 2014.

[6] M. Saraswat, "Genetic Algorithm for optimization using MATLAB," International Journal of Advanced Research in Computer Science, vol. 4, 2013.

[7] T. Bäck and H.-P. Schwefel, "An overview of evolutionary algorithms for parameter optimization," Evolutionary computation, vol. 1, pp. 1-23, 1993.

[8] J. H. Holland, Adaptation in Natural and Artificial Systems The University of Michigan Press, 1975.

[9] Z. Michalewicz, Genetic Algorithms + Data Structures = Evolution Programs. New York: Springer-Verlag, 1944.

[10] a. R. C. M. Gen, Genetic Algorithms and Engineering Optimization. New York: Wiley, 2000.

[11] L. Davis, The handbook of genetic algorithms. New York: Van Nostrand Reinhold, 1991.

[12] D. E. Goldberg, Genetic Algorithms in Search, Optimization and Machine Learning. MA: AddisonWesley, Reading, 1989.

[13] M. S. Al-Ashhab, T. Attia, and S. M. Munshi, "Multi-Objective Production Planning Using Lexicographic Procedure," American Journal of Operations Research, vol. 7, p. 174, 2017.

[14] Palisade. (2010). Guide to Using Evolver. Available: www.crystalballservices.com

[15] M. Al-Ashhab, S. Azam, S. Munshi, and T. M. Abdolkader, "A Multi-Period MPS Optimization Using Linear Programming and Genetic Algorithm with Capacity Constraint.".

*Corresponding author.

E-mail address: msashhab@uqu.edu.sa/hafadag@uqu.edu.sa 